\title{
Probing the mucoadhesive interactions between porcine gastric mucin and some water-soluble polymers
}

Article

Accepted Version

Albarkah, Y. R., Green, R. J. and Khutoryanskiy, V. V. (2015) Probing the mucoadhesive interactions between porcine gastric mucin and some water-soluble polymers.

Macromolecular Bioscience, 15 (11). pp. 1546-1553. ISSN 1616-5187 doi: https://doi.org/10.1002/mabi.201500158 Available at https://centaur.reading.ac.uk/40727/

It is advisable to refer to the publisher's version if you intend to cite from the work. See Guidance on citing.

Published version at: http://onlinelibrary.wiley.com/doi/10.1002/mabi.201500158/abstract

To link to this article DOI: http://dx.doi.org/10.1002/mabi.201500158

Publisher: Wiley

All outputs in CentAUR are protected by Intellectual Property Rights law, including copyright law. Copyright and IPR is retained by the creators or other copyright holders. Terms and conditions for use of this material are defined in the End User Agreement.

www.reading.ac.uk/centaur 
Central Archive at the University of Reading

Reading's research outputs online 


\title{
Probing the mucoadhesive interactions between porcine gastric mucin and some water-soluble polymers
}

\author{
Yasser A. Albarkah, Rebecca J. Green, Vitaliy V. Khutoryanskiy* \\ Reading School of Pharmacy, University of Reading, Whiteknights PO Box 224, Reading, \\ RG6 6AD, United Kingdom
}

\begin{abstract}
This study investigated the structural features of porcine gastric mucin (PGM) in aqueous dispersions and its interactions with several water-soluble polymers (poly(acrylic acid), poly(methacrylic acid), poly(ethylene oxide) and poly(ethylene glycol)) using isothermal titration calorimetry, turbidimetric titration, dynamic light scattering and transmission electron microscopy. It was established that poly(acrylic acid) (PAA, $450 \mathrm{kDa})$ and poly(methacrylic acid) (PMAA, $100 \mathrm{kDa}$ ) exhibit strong specific interactions with PGM causing further aggregation of its particles, whilst PAA (2 kDa), poly(ethylene oxide) (1000 $\mathrm{kDa})$ and poly(ethylene glycol) $(10 \mathrm{kDa})$ do not show any detectable effects on mucin. Sonication of mucin dispersions prior to their mixing with PAA (450 kDa) and PMAA (100 $\mathrm{kDa}$ ) leads to more pronounced intensity of interactions. In the presence of $4-8 \mathrm{~mol} / \mathrm{L}$ of urea these specific interactions are completely inhibited. The nature of the interactions between porcine gastric mucin and poly(carboxylic acids) is believed to be hydrogen bonding.
\end{abstract}


Key words: water-soluble polymers, porcine gastric mucin, mucoadhesion, Isothermal Titration Calorimetry, hydrogen bonding

\section{Introduction}

Mucosal membranes are moist surfaces in the human body exposed to the external environment. These include the gastrointestinal, respiratory and genitourinary tracts as well as the mouth, the nostrils and the eyes. They serve to protect the body from chemical and mechanical damage. Additionally they ensure lubrication and wetting of the epithelial surfaces. ${ }^{[1-3]}$

Mucoadhesion can be defined as the interfacial attractive interactions between the polymeric materials in a dosage form and a mucus layer that covers mucosal tissues. Mucoadhesion has a significant role in drug delivery via mucosal routes of administration by holding a dosage form at the potential site of action and providing improved retention, drug absorption and enhanced bioavailability. ${ }^{[4]}$ Furthermore, mucoadhesive materials can be used as curative agents to cover and protect damaged tissues (such as gastric ulcers or lesions of oral mucosa) or work as coating agents (oral cavity, eye and vagina). ${ }^{[5]}$

Mucins are glycoproteins with a high molecular weight ranging within 0.5-40 MDa; they are important components of the mucus gel present on mucosal surfaces. There are two main types of mucin which coat the epithelial cells of the mucosal tissue: membrane-bound and secretory mucins. These form a fully hydrated viscoelastic gel layer known as mucus. The majority of mucins are negatively charged due to the presence of carboxylate groups and ester sulphates. $^{[3,6]}$ 
Mucoadhesive materials are usually hydrophilic polymers capable of interacting with mucins and forming physical contacts such as hydrogen bonding, electrostatic attraction forces and hydrophobic effects. These polymers could be of cationic, anionic, amphoteric or neutral nature. ${ }^{[2,7]}$

A number of studies have been reported to explore the non-covalent interactions between mucins and various water-soluble polymers. The majority of these studies were focused on the interactions between commercially available porcine gastric or bovine submaxiliary mucins (Sigma-Aldrich) and cationic synthetic and natural polymers as well as dendrimers. ${ }^{[8-12]}$

Sogias et $\mathrm{al}^{[10]}$ have studied the interactions between porcine gastric mucin and chitosan using a combination of dynamic light scattering, transmission electron microscopy, zetapotential measurements and turbidimetric titration in the aqueous media containing inorganic salt, ethanol or urea. They have established that the mucoadhesive interactions have a complex nature with contributions from electrostatic attraction, hydrogen bonding and hydrophobic effects. The presence of inorganic salt, ethanol or urea in solutions could selectively inhibit the contribution of particular effects into these interactions. Similar study was reported for the interactions between porcine gastric mucin and synthetic quaternary ammonium methacrylate copolymers. ${ }^{[13]}$ Recently the interactions between chitosan and porcine gastric mucin were also studied by Menchicchi et $\mathrm{al}^{[11]}$ and by Meng-Lund et $\mathrm{al}^{[14]}$ using isothermal titration calorimetry (ITC). It was established that the binding of chitosan to mucin is a two-stage process with a switch from an exothermic to an endothermic effect depending on the polymer-mucin ratio. 
Some other studies also reported the interactions between mucins and anionic polymers such as poly(acrylic acid), its weakly cross-linked derivatives (e.g. Carbopols®) and also some anionic polysaccharides (alginate, dextran sulphate, hyaluronic acid, carboxymethylcellulose, pectin, etc). ${ }^{[15-18]}$ The study of interactions between anionic polymers such as Carbopol 934P, a weakly cross-linked derivative of poly(acrylic acid), and

porcine gastric mucin was previously reported by Patel et al. ${ }^{[15]}$ They used a range of physicochemical techniques such as infrared, ${ }^{1} \mathrm{H}$ and ${ }^{13} \mathrm{C}$ nuclear magnetic resonance, and $\mathrm{X}$-ray photoelectron spectroscopies as well as differential scanning calorimetry and established the formation of hydrogen bonds between the amide groups in mucin and unionized carboxylic groups in poly(acrylic acid).

In the present work we investigated the structural features of porcine gastric mucin and its interactions with linear poly(acrylic acid), poly(methacrylic acid), poly(ethylene oxide) and poly(ethylene glycol) in aqueous dispersions using isothermal titration calorimetry, turbidimetric titration, dynamic light scattering and transmission electron microscopy. To the best of our knowledge, this is the first study reporting the thermodynamic parameters of interactions between porcine gastric mucin and poly(carboxylic acids) in aqueous solutions.

\section{Materials and methods}

\subsection{Materials}

Porcine gastric mucin (PGM) type III, poly(acrylic acid) (PAA, 2 and $450 \mathrm{kDa}$ ), potassium di-hydrogen orthophosphate, polyethylene oxide (PEO, $1000 \mathrm{kDa}$ ), polyethylene glycol (PEG, $10 \mathrm{kDa}$ ), and urea were purchased from Sigma-Aldrich, UK. Poly(methacrylic acid) 
(PMAA, $100 \mathrm{kDa}$ ) was purchased from PolyScience, Germany, and orthophosphoric acid was sourced from Fluka, UK. All chemicals were used without further purification.

\subsection{Sample preparation}

All experiments were performed with 1 and $10 \mathrm{mg} / \mathrm{mL}$ mucin dispersions. These dispersions behaved like Newtonian non-viscous fluids. A two-step sample preparation technique was used to prepare mucin dispersions. PGM was dispersed in phosphate buffer, which was prepared by dissolving $34 \mathrm{~g}$ of potassium dihydrogen orthophosphate in $250 \mathrm{~mL}$ of ultrapure water with subsequent adjustment of $\mathrm{pH}$ to 3.0 using $1 \mathrm{~mol} / \mathrm{L}$ orthophosphoric acid (approximately $3.75 \mathrm{~mL}$ ). Note that $\mathrm{pH} 3.0$ is within physiological range of $\mathrm{pHs}$ in the stomach (1.6 to 7.2). ${ }^{[7]}$ PGM dispersions were stirred for 1 hour at room temperature and then $5 \mathrm{~mL}$ of each sample was sonicated with an exponential microprobe (MSE Ultrasonic instrument, UK, sonication amplitude 6 microns peak to peak) for different times $(0,5$ and 15 min) and left stirring overnight before each experiment. Ultrapure water from a Purelab UHQ water purifier, ELGA, $\mathrm{UK}(\Omega<18 \mathrm{~cm})$ was used in all experiments.

\subsection{Isothermal titration calorimetry (ITC)}

Binding interactions between PGM and different polymers (PAA 2 and $450 \mathrm{kDa}$, and PMAA $100 \mathrm{kDa}$ ) were studied using a MicroCalTM ITC-200 instrument (GE Healthcare, UK). Polymer solutions were loaded into the syringe $(40 \mu \mathrm{L})$ and titrated into mucin dispersions loaded in $200 \mu \mathrm{L}$ calorimeter sample cell. The reference cell was filled with ultrapure water. Titration measurements were performed automatically by the instrument,

where $2 \mu \mathrm{L}$ portions from the syringe were injected automatically into the sample cell every $80 \mathrm{sec}$. All ITC experiments were conducted at $25^{\circ} \mathrm{C}$. OriginLab® version 7.0 software was 
used for the analysis of results and one-site binding model (n identical sites) was applied. ${ }^{[19]}$ The molecular weight of PGM used for calculations of ITC parameters was assumed to be $1.25 \times 10^{6} \mathrm{Da}^{[20]}$

\subsection{Dynamic light scattering (DLS)}

The effect of sonication on the particle size distribution of mucin dispersions was studied using DLS. Initially, mucin dispersions ( $1 \mathrm{mg} / \mathrm{mL})$ were sonicated using a sono-probe (MSE Ultrasonic instrument, UK) for 5 and 15 mins at $25^{\circ} \mathrm{C}$. The size distribution of mucin dispersions was measured using a Nano-ZS Zetasizer (Malvern Instruments, UK) at $25^{\circ} \mathrm{C}$. A refractive index 1.15 and absorbance of 0.001 was used for all measurements. Each sample was measured three times and the results are presented as the mean values \pm standard deviation $(\mathrm{n}=3)$.

\subsection{Turbidimetric titration}

The interaction between PGM and the polymers was also investigated using turbidimetric titration. A $1 \mathrm{mg} / \mathrm{mL}$ dispersion of PGM was prepared as described in Section 2.2 and titrated with $10 \mathrm{mg} / \mathrm{mL}$ of each polymer. In each titration, $5 \mathrm{~mL}$ of PGM dispersion was titrated with solutions of each polymer separately, under continuous stirring for $1 \mathrm{~min}$. The changes in turbidity were monitored at $400 \mathrm{~nm}$ with a Jasco V-530 UV/vis spectrophotometer (Jasco, UK). All of the measurements were performed in triplicate at room temperature and the results are presented as mean values \pm standard deviation. To study the effect of urea at $\mathrm{pH} 3.0,1 \mathrm{mg} / \mathrm{mL}$ PGM dispersions were prepared in $0-8 \mathrm{~mol} / \mathrm{L}$ urea aqueous solutions instead of phosphate buffer. $\mathrm{pH}$ of these urea-containing solutions was adjusted to 3.0 by addition of $1 \mathrm{~mol} / \mathrm{L} \mathrm{HCl}$. 


\subsection{Transmission electron microscopy}

A $10 \mathrm{mg} / \mathrm{mL}(1 \mathrm{w} / \mathrm{v} \%)$ mucin dispersion was prepared in phosphate buffer, and adjusted to pH 3.0 with small quantities of $1 \mathrm{~mol} / \mathrm{L} \mathrm{HCl}$. Mucin suspensions were pipetted onto a copper grid. The sample was then stained with $1 \mathrm{w} / \mathrm{v} \%$ of uranyl acetate solution and allowed to dry using a filter paper. Imaging of the samples was then carried out under vacuum with a JEOL JEM-2010 microscope with an accelerating voltage of $120 \mathrm{kV}$.

\subsection{Statistical analysis}

All of the values are presented as mean \pm standard deviation. The ITC data which was used to study the effect of sonication on the interactions between mucin and PAA was statistically analysed using MINITAB-17. Significance of the data was evaluated by a oneway ANOVA test. The criterion for statistical significance was defined as $p<0.05$.

\section{Results and discussion}

\subsection{Investigation into the structure and properties of porcine gastric mucin in aqueous dispersions}

\subsubsection{Effect of sonication on the size distribution of mucin}

Mucin dispersions ( $1 \mathrm{mg} / \mathrm{mL}, \mathrm{pH} \mathrm{3.0)}$ sonicated for 0,5 , and $15 \mathrm{~min}$ at $25^{\circ} \mathrm{C}$ were studied using DLS. Figure 1 shows that the non-sonicated mucin dispersion exhibits a bimodal size distribution, whereby producing two different size populations with z-averages of $531 \pm 85$ and $1480 \pm 285 \mathrm{~nm}$. After sonication of mucin dispersions for $5 \mathrm{~min}$, another bimodal size 
distribution is obtained. However, the peaks have shifted, giving one peak at $58 \pm 14 \mathrm{~nm}$ and another at $615 \pm 96 \mathrm{~nm}$. Despite the larger z-average presented in the second peak, the overall distribution is smaller, and the particles are smaller than $1 \mu \mathrm{m}$. Furthermore, sonication of mucin for 15 mins resulted in an almost mono-modal particle size distribution with a $\mathrm{z}$-average size of $459 \pm 73 \mathrm{~nm}$. Sonication causes an initial disaggregation of mucin particles with the formation of smaller species. Further DLS measurements showed that some of these particles remain un-aggregated but some gradually re-aggregate to form larger agglomerates. The formation of PGM particles with monomodal particle distribution was not therefore achieved in all experiments with 15 min sonication as mucin dispersion is a highly dynamic system undergoing continuous transformations; however a reduction in size compared to the non-sonicated samples was.

We have also probed the effect of sonication on mucin dispersions with different concentrations and different $\mathrm{pHs}$ (data not shown). The results revealed similar redistribution of particle sizes upon sonication. The distributions presented here are in good agreement with our previous studies, which also looked at $1 \mathrm{mg} / \mathrm{mL}$ PGM dispersions at different pHs. ${ }^{[10,13]}$ Typically, mucin aggregates of larger size were observed at lower $\mathrm{pHs}$.

Sonicated mucin dispersions reveal a re-distribution of particle sizes which is likely related to disaggregation of some particles with liberation of smaller species with activated surfaces. These smaller particles can promote further agglomeration and formation of larger aggregates by interactions with other parts of the mucin network. The mechanism of disaggregation and re-aggregation of mucin particles caused by sonication is schematically shown in Figure 2. 
The dynamic nature of mucin particles and their continuous disaggregation and reaggregation was also demonstrated in experiments with filtration when non-sonicated mucin dispersion was passed through $0.2 \mu \mathrm{m}$ filter and it still showed the presence of particles whose size exceeds $0.2 \mu \mathrm{m}$ (data is not shown). This observation confirms that mucin particles could be either deformed or disaggregated to pass $0.2 \mu \mathrm{m}$ filter pores but they reaggregate again to form larger particles.

TEM was also used to study the changes that occurred with mucin particles. Earlier Fiebrig et $\mathrm{al}^{[21]}$ have reported the TEM study of porcine gastric mucin and the products of its interactions with chitosan. In the sample of mucin they observed the presence of swollen 50$150 \mathrm{~nm}$ structures joined by $200-400 \mathrm{~nm}$ long and thin linker regions. It was also demonstrated that the technique used for sample preparation has a substantial effect on the mucin structural features observed in TEM. The other authors have reported the presence of a dumbbell-shape structures in mucin samples. ${ }^{[22,23]}$ Our TEM results confirm that nonsonicated mucin is a very polydisperse system with the presence of numerous globular shape objects (around $25 \mathrm{~nm}$ in diameter) linked with bridges of around $25-75 \mathrm{~nm}$ in length (Figure 3). This result is in excellent agreement with the data reported by Znamenskaya et $\mathrm{al}^{[23]}$ : they used atomic force microscopy and observed the presence of dumbbell-like structures with $20 \mathrm{~nm}$ globules connected with $20-150 \mathrm{~nm}$ thin linker regions. The sonication of mucin dispersions results in a change in appearance of these particles and partial disappearance of the dumbbell shape objects. After sonication the globular mucin structures become directly linked to each other without any bridges present. The disappearance of bridges between mucin globules after sample sonication is clearly observed both in case of $1 \mathrm{mg} / \mathrm{mL}$ and $10 \mathrm{mg} / \mathrm{mL}$ mucin dispersions. Some differences between the structures of mucin reported in the literature ${ }^{[21]}$ and our results are likely related 
to the different sample preparation technique used for TEM experiments and mucin purification (e.g. we have used porcine gastric mucin samples received from Sigma-Aldrich, whilst Fiebrig et al $^{[21]}$ have isolated and purified their samples from fresh stomach mucosa).

\subsubsection{Effect of sonication on the interactions between mucin and PAA}

Initially, isothermal titration calorimetry (ITC) was used to investigate the effect of mucin sonication on its interaction with PAA. ITC is a very powerful method to study bimolecular interactions. It has been widely used to study interactions of polymers/biopolymers with other polymers, surfactants, small molecules, etc. ${ }^{[19,24-26]}$ It measures molecular interactions in solution in terms of changes in heat, which can be exothermic or endothermic depending on the nature of the interacting species. Recently ITC has been successfully used to study mucoadhesive interactions of porcine gastric mucin with epigallocatechin gallate ${ }^{[27]}$ and with chitosan. ${ }^{[11,14]}$

Three $10 \mathrm{mg} / \mathrm{mL}$ mucin dispersions were prepared at $\mathrm{pH}$ 3.0. Two of the samples were subjected to sonication for 5 and $15 \mathrm{~min}$, respectively. Samples were then titrated with 1 $\mathrm{mg} / \mathrm{mL}$ of PAA solution (Figure 4). ITC raw data showed the evidence of exothermic interaction between PAA and mucin (Figure 2s, Supporting information). Exothermic effects are often associated with hydrogen bonding, ${ }^{[24]}$ which indicates that this could be a predominant nature of mucin-PAA interactions. This conclusion is in good agreement with Patel et al. ${ }^{[15]}$ Sonication was found to have a significant $(\mathrm{p}<0.05)$ effect on the intensity of PAA-mucin interactions: stronger exothermic events are observed for sonicated mucin samples with higher $\Delta \mathrm{H}$ values (Table 1). Sonication resulted in mucin particles with a smaller size and, therefore, a greater surface area available for potential interactions with PAA; thus, there is an alteration in the interaction intensity. The effect of surface area on the 
interactions indicates that the macromolecules of PAA predominantly interact with the available surface of mucin particles and do not penetrate into the bulk structure or break open the mucin aggregate. This feature makes mucin-polymer interactions a unique system to study by ITC and show that the dimensional and physical properties of the mucin sample cannot be ignored. The majority of previous applications of ITC were focused on molecularly dispersed systems such as polymer-polymer complexes, ${ }^{[24,28]}$ protein-small molecules, ${ }^{[29,30]}$ DNA/RNA - dendrimer binding, ${ }^{[31]}$ metal ion - small chelate molecules, etc. ${ }^{[26]}$ The recent publications on the use of ITC to study porcine gastric mucin interactions with chitosan or with epigallocatechin gallate either used a soluble and purified fraction of mucin extracted from commercial samples ${ }^{[11,27]}$ or simply disregarded the colloidal nature of mucin dispersions. ${ }^{[14]}$ Our data indicate that ITC could potentially be used to study interactions in systems involving colloidal particles; however, care must be taken in interpretation of the results where only particle surface groups will be involved in these interactions.

\subsection{Interactions between PGM and different water-soluble polymers}

The interaction between PGM and different water-soluble polymers was studied using a selection of physicochemical methods as shown below. All these experiments were performed with PGM dispersions sonicated for $15 \mathrm{~min}$.

\subsubsection{Turbidimetric titration}

Turbidity measurements were used to monitor the effects of PAA, PMAA, PEO and PEG on mucin dispersions. The addition of PAA (450 kDa) solutions to mucin dispersions results in an initial increase in dispersion turbidity until $[\mathrm{PAA}] /[$ mucin] weight ratio reaches 
approximately 0.5 ; this increase is likely related to mucin particles aggregation. The further addition of PAA to mucin leads to a gradual and linear reduction in dispersion turbidity, which is related to the dilution of mucin aggregates. This aggregation of mucin particles upon addition of PAA can be observed when mucin dispersions of different concentrations are used (Figure 1s, Supporting information). Similar behaviour is observed upon addition of PMAA to mucin dispersions; however, the aggregation in this case is less pronounced. The addition of a small molecular weight PAA ( $2 \mathrm{kDa})$ to mucin does not cause any increase in turbidity and gradually results in its reduction, indicating the absence of any specific interactions. A reasonable explanation for this effect is that the small molecular weight PAA does not bind to mucin particles and could not cause their aggregation because its molecular weight is below the critical chain length of this polymer. For the polymer to promote aggregation of the system a cooperative interaction is seen where the presence of long polymer chains is needed. A similar lack of interaction of PAA ( $2 \mathrm{kDa})$ was reported previously in a study of the effect of molecular weight of PAA on its intermacromolecular complex formation with some non-ionic polymers such as hydroxyethylcellulose in aqueous solutions. ${ }^{[32]}$

Like PAA $(2 \mathrm{kDa})$, the turbidity of mucin dispersions decreased in a linear fashion upon addition of PEO and PEG. This would reflect the inability of PEG and PEO to form strong hydrogen bonds with mucin. These observations are in agreement with the findings by Wang et al ${ }^{[33]}$ and Irmukhametova et al, ${ }^{[34]}$ who reported that PEGs with low molecular weights $(2 \mathrm{kDa}$ and $5 \mathrm{kDa})$ are non-mucoadhesive. 


\subsubsection{ITC}

ITC was also used to assess the effect of molecular weight and the polymer nature on the interactions with PGM (Figure 6). Initially, phosphate buffer was titrated against $10 \mathrm{mg} / \mathrm{mL}$ PAA (450 kDa) and used as a control. ITC data agreed with the results obtained from turbidimetric measurements. The ITC results recorded for titration of PGM with PAA (2 kDa) show little difference from the control experiment when PAA sample was simply diluted with phosphate buffer. This confirms that there is no interaction between PGM and PAA (2 kDa). In contrast, the interaction between PGM and PAA (450 kDa) was exothermic under the experimental conditions. The effect of the polymer nature showed that the interaction of PAA (450 kDa) with PGM is more pronounced compared to PMAA (100 $\mathrm{kDa})$. The $\Delta \mathrm{H}$ value recorded for the interaction of PAA (450 $\mathrm{kDa}$ ) with PGM was higher than the $\Delta \mathrm{H}$ of PMAA (100 kDa) - PGM; this is in line with turbidimetric results and indicates weaker interactions involving more hydrophobic PMAA (Table 2).

\subsection{Effect of urea on the interactions between PGM and PAA}

The interactions between PAA $(450 \mathrm{kDa})$ and PGM were also studied in solutions containing different concentrations of urea (1-8 mol/L) using both turbidimetric titration and ITC. Preliminary experiments showed that addition of urea to PGM dispersions changes the structure of mucin particles: when urea concentration increases from 0 to $2 \mathrm{~mol} / \mathrm{L}$, this results in higher turbidity values, indicating partial swelling of mucin particles. A further increase in urea concentration from 4 to $8 \mathrm{~mol} / \mathrm{L}$ results in a dramatic reduction of initial turbidity of mucin dispersions. Urea is known to act as a strong competitor for hydrogen bonds and its presence in mucin dispersions may cause the partial disruption of intra-particle hydrogen bonds that may hold smaller mucin particles together ${ }^{[35]}$. This is in agreement 
with our previous report ${ }^{[10]}$ and is also confirmed by additional dynamic light scattering measurements of mucin dispersions in solutions containing different concentrations of urea (Figure 4s, Supporting Information). An initial swelling of mucin particles is observed in 1 and $2 \mathrm{~mol} / \mathrm{L}$ urea; a further increase in urea concentration results in reduction of mucin size.

At low concentrations of urea in solution $(<4 \mathrm{~mol} / \mathrm{L})$ the interaction between PAA (450 $\mathrm{kDa}$ ) and PGM is still taking place as evidenced from both turbidimetric (Figure 7) and ITC (Figure 8) results. At higher urea concentrations $(4-8 \mathrm{~mol} / \mathrm{L})$ the addition of PAA to PGM does not cause any further aggregation and results in a linear decrease in dispersion turbidity related to simple dilution. Similarly, the ITC data indicate that the mixing PGM and PAA in 1 and $2 \mathrm{~mol} / \mathrm{L}$ urea solutions still results in exothermic effects, confirming the presence of interactions; a dramatic decrease in the interaction intensity is observed at $2 \mathrm{~mol} / \mathrm{L}$ compared to $1 \mathrm{~mol} / \mathrm{L}$ of urea. At 4,6 and $8 \mathrm{~mol} / \mathrm{L}$ of urea the mixing of mucin with PAA shows very weak endothermic effects similar to a negative control, which is consistent with the system simple dilution.

Table 3 summarised the binding constants and changes in enthalpy recorded for the interactions between PAA $(450 \mathrm{kDa})$ and mucin in solutions of urea of different concentrations. It is interesting to note that the interaction parameters recorded in $1 \mathrm{~mol} / \mathrm{L}$ urea are significantly higher than $\mathrm{K}$ and $\Delta \mathrm{H}$ observed for urea-free solutions. This is likely related to additional swelling of mucin particles in $1 \mathrm{~mol} / \mathrm{L}$ solution of urea, which means their functional groups more available for interactions with PAA. A further increase in urea concentration results in a dramatic drop of binding affinity and switch from exothermic $\Delta \mathrm{H}$ to endothermic values. 


\section{Conclusions}

Mucin is a complex colloidal polydisperse system which undergoes desaggregation/aggregation upon sonication or filtration. Nearly monodisperse samples can potentially be prepared using sonication. Mucin also shows specific interactions with PAA (450 kDa) and PMAA (100 kDa), resulting in aggregation of its particles and formation of larger agglomerates. These interactions have exothermic nature and are believed to be due to hydrogen bonding between carboxylic groups of the polymer and hydroxyl groups in the oligosaccharide residues present in mucin. It was demonstrated that sonicated samples with smaller size and larger surface area of mucin particles result in more pronounced interactions with PAA (450 kDa) and PMAA (100 kDa). Hydrogen bonding is responsible for mucin and PAA interactions, and it was greatly affected by the addition of urea, as the interaction can be completely inhibited at high urea concentrations. A small molecular weight PAA (2 kDa) as well as PEG (10 kDa) and PEO (1000 kDa) did not show any noticeable interactions with mucin.

\section{Supporting Information}

Raw ITC data for the effects of sonication, polymer nature and urea content in solutions on the interactions; dynamic light scattering data on dispersions of PGM in urea solutions.

\section{Abbreviations}

PAA, poly(acrylic acid); PMAA, poly(methacrylic acid); PEG, poly(ethylene glycol); PEO, poly(ethylene oxide); PGM, porcine gastric mucin; DLS, dynamic light scattering; ITC, isothermal calorimetry titration; TEM, transmission electron microscopy. 


\section{Acknowledgments}

The authors would like to thank the Embassy of Saudi Arabia for funding this project and are grateful to Dr Peter Harris for his help with TEM experiments and Mr Andy Dodson for providing training in ITC. Chemical Analysis Facility (University of Reading) is acknowledged for access to TEM and ITC.

\section{References}

[1] G. P. Andrews, T. P. Laverty, D. S. Jones, Eur J Pharm Biopharm 2009, 71, 505.

[2] V. V. Khutoryanskiy, Macromol Biosci 2011, 11, 748.

[3] N. A. Peppas, J. J. Sahlin, Biomaterials 1996, 17, 1553.

[4] V. V. Khutoryanskiy, Mucoadhesive Materials and Drug Delivery Systems, Wiley, 2014, 352.

[5] H. Batchelor, The Drug Delivery Companies Report 2004, 16.

[6] J. D. Smart, Adv Drug Deliv Rev 2005, 57, 1556.

[7] A. Sosnik, J. das Neves, B. Sarmento, Progress in Polymer Science 2014, 39, 2030.

[8] S. Rossi, F. Ferrari, M. C. Bonferoni, C. Caramella, Eur J Pharm Sci 2000, 10(4), 251.

[9] S. Rossi, F. Ferrari, M. C. Bonferoni, C. Caramella, Eur J Pharm Sci 2001, 12(4), 479. [10] I. A. Sogias, A. C. Williams, V. V. Khutoryanskiy, Biomacromolecules 2008, 9, 1837.

[11] B. Menchicchi, J. P. Fuenzalida, K. B. Bobbili, A. Hensel, M. J. Swamy, F. M. Goycoolea, Biomacromolecules 2014, 15, 3550.

[12] P. C. Griffiths, P. Occhipinti, C. Morris, R. K. Heenan, S. M. King, M. Gumbleton, Biomacromolecules 2010, 11(1), 120.

[13] N. A. Fefelova, Z. S. Nurkeeva, G. A. Mun, V. V. Khutoryanskiy, Int. J. Pharm 2007, $339,25$.

[14] E. Meng-Lund, C. Muff-Westergaard, C. Sander, P. Madelung, J. Jacobsen, Int. J. Pharm 2014, 461, 280.

[15] M. M. Patel, J. D. Smart, T. G. Nevell, R. J. Ewen, P. J. Eaton, J. Tsibouklis, Biomacromolecules 2003, 4, 1184.

[16] C.T. Nordgard, K.I. Draget, Biomacromolecules 2011, 12, 3084.

[17] M. Sletmoen, G. Maurstad, C.T. Nordgard, K.I. Draget, B.T. Stokke, Soft Matter 2012, 8,8413 .

[18] B. Menchicchi, J.P. Fuenzalida, A. Hensel, M.J. Swamy, L. David, C. Rochas, F.M. Goycoolea, Biomacromolecules 2015, 16, 924.

[19] M. W. Freyer, E. A. Lewis, Methods Cell Biol 2008, 84, 79.

[20] K. Jumel, I. Fiebrig, S. E. Harding, Int. J. Biol. Macromol 1996, 18, 133.

[21] I. Fiebrig, S. E. Harding, A. J. Rowe, S. C. Hyman, S. S. Davis, Carbohydrate Polym 1995, 28, 239.

[22] G. E. Yakubov, A. Papagiannopoulos, A. Rat, T. Waigh, Biomacromolecules 2007, $8(11), 3467$.

[23] Y. Znamenskaya, J. Sotres, J. Engblom, T. Arnebrant, V. Kocherbitov, J Phys Chem B 2012, 116(16), 5047.

[24] S. C. Bizley, A. C. Williams, V. V. Khutoryanskiy, Soft Matter 2014, 10, 8254. 
[25] R. Ghai, R. J. Falconer, B. M. Collins, Journal of Molecular Recognition 2012, 25(1), 32.

[26] P. W. J. Morrison, V. V. Khutoryanskiy, Int. J. Pharm 2014, 472, 56.

[27] Y. Zhao, L. Chen, G. Yakubov, T. Aminiafshar, L. Han, G. Lian, J. Phys. Chem. B 2012, 116, 13010 .

[28] O. V. Khutoryanskaya, A. C. Williams, V. V. Khutoryanskiy, Macromolecules 2007, 40, 7707.

[29] M. A. Dobreva, R. J. Green, I. Mueller-Harvey, J.-P. Salminen, B. J. Howlin, R. A. Frazier, J. Agric. Food Chem 2014, 62 (37), 9186.

[30] M. D. Lad, V. M. Ledger, B. Briggs, R. J. Green, R. A. Frazier, Langmuir 2003, 19 (12), 5098.

[31] L. B. Jensen, K. Mortensen, G. M. Pavan, M. R. Kasimova, D. K. Jensen, V. Gadzhyeva, H. M. Nielsen, C. Foged, Biomacromolecules 2010, 11 (12), 3571.

[32] Y. J. Bo, V. V. Khutoryanskiy, G. A. Mun, Z. S. Nurkeeva, Polym. Sci. Ser A 2002, 44, 1094.

[33] Y. Wang, K. L. Samuel, J. S. Suk, A. Pace, R. Cone, J. Hanes, Angewandte Chemie 2008, 47, 9726

[34] G. S. Irmukhametova, G. A. Mun, V. V. Khutoryanskiy, Langmuir 2011, 27, 9551.

[35] R. Martin, M. Litt, C. Marriott, Am Rev Respir Dis 1980, 121(3), 495. 


\section{FIGURES}
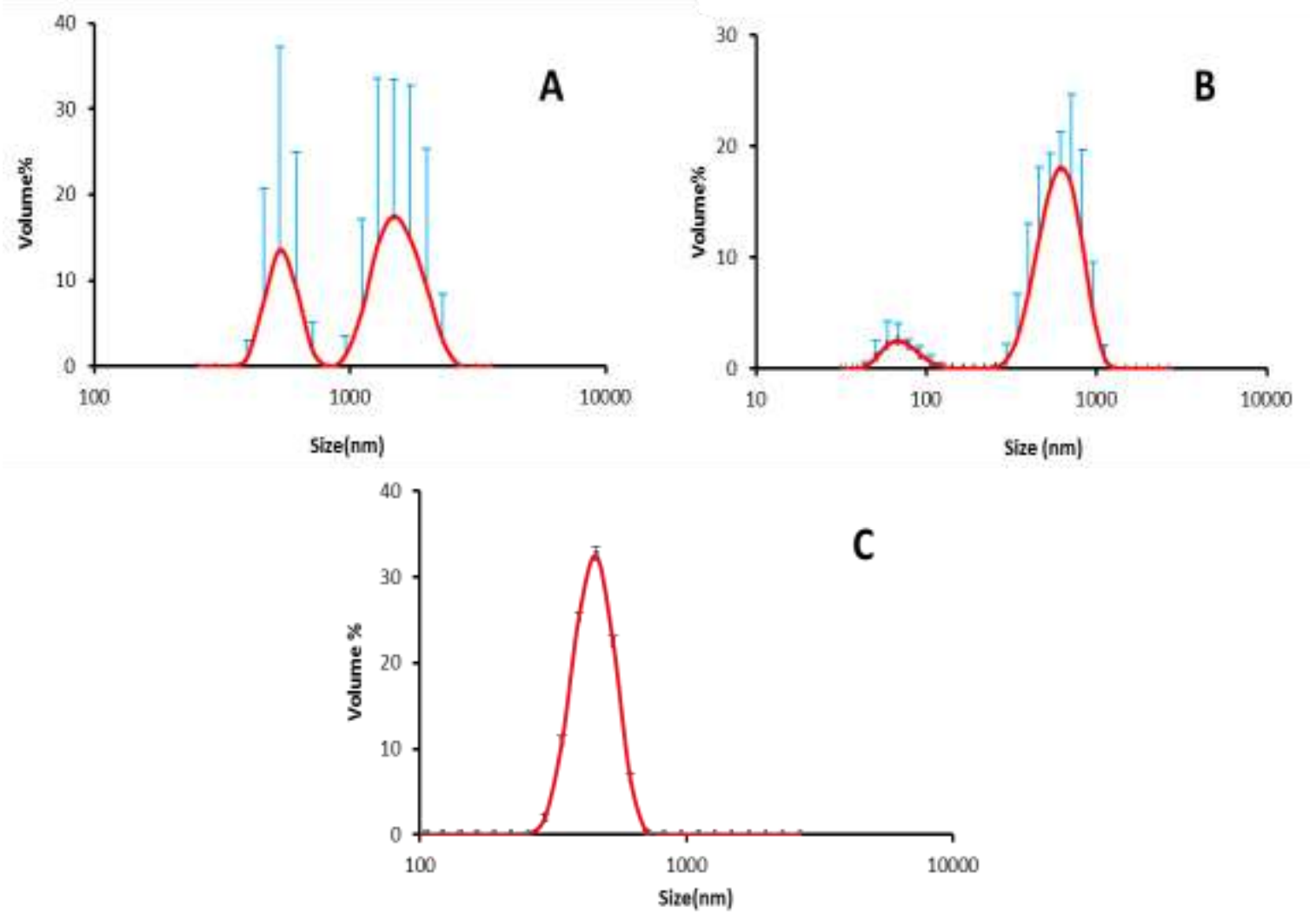

Figure 1 Size distributions of mucin dispersions as determined by DLS. $0.1 \mathrm{mg} / \mathrm{mL}$ PGM aqueous dispersions were sonicated for different times: (A): no sonication, (B): sonication for $5 \mathrm{~min}$, and $(\mathrm{C})$ : sonication for $15 \mathrm{~min}$. These size distributions represent the mean result of three independent experiments. 


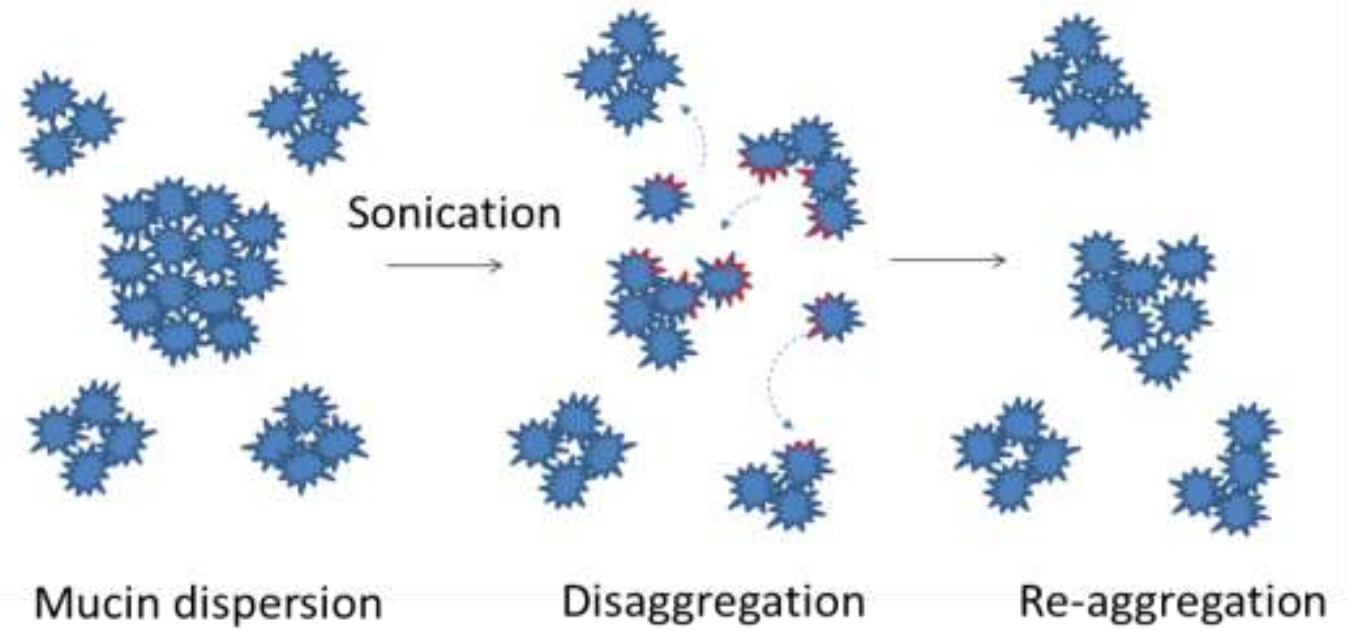

Figure 2 Schematic diagram illustrating the effect of sonication on the disaggregation/aggregation of mucin particles. 

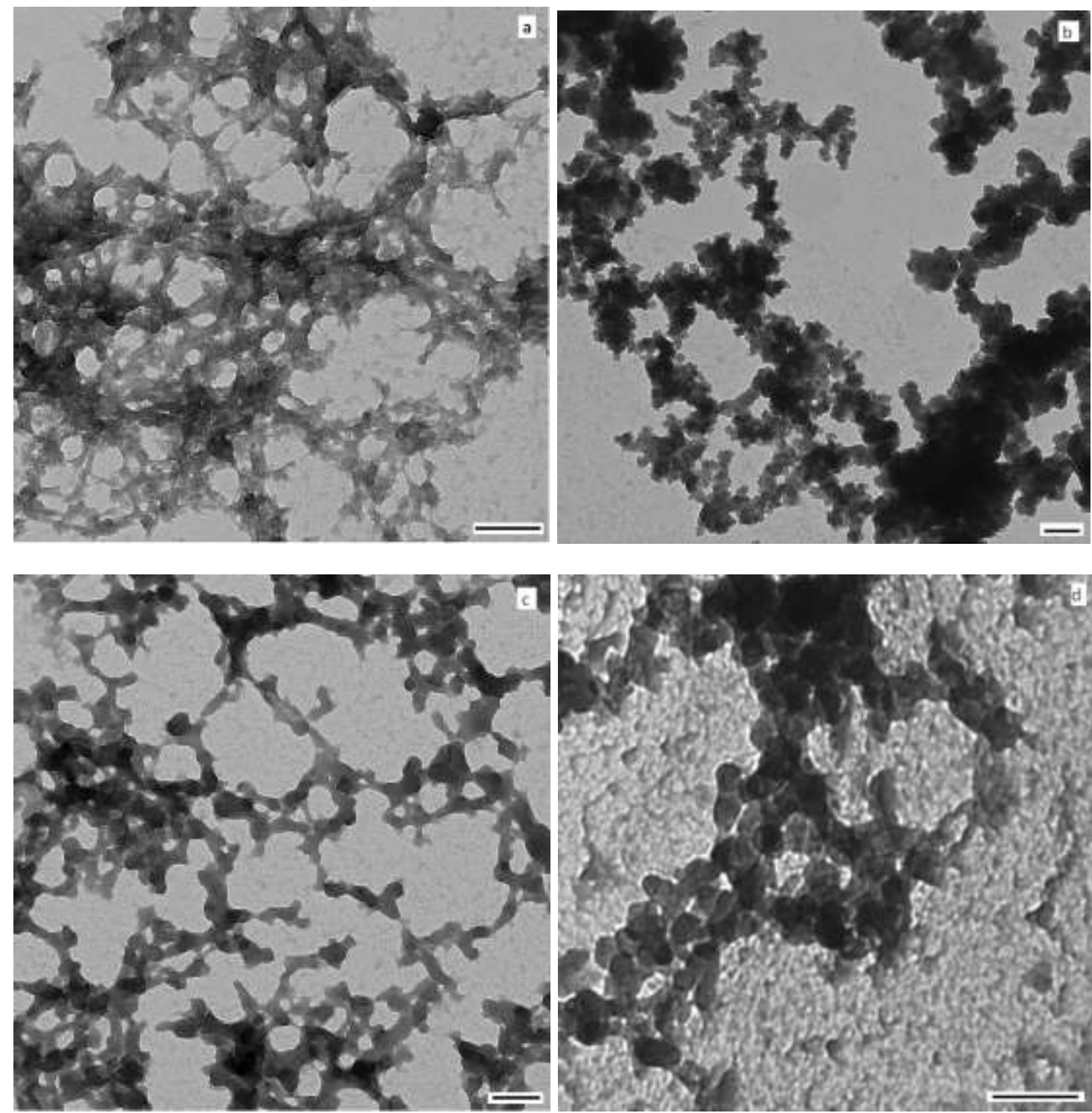

Figure 3 Transmission electron micrographs of $1 \mathrm{mg} / \mathrm{mL}$ of non-sonicated mucin (a) and sonicated mucin (b); and $10 \mathrm{mg} / \mathrm{mL}$ non-sonicated mucin (c) and sonicated mucin (d). All samples were prepared at $\mathrm{pH} 3.0$ and sonication of (b) and (d) was done for $15 \mathrm{~min}$. Size bar is $100 \mathrm{~nm}$. 


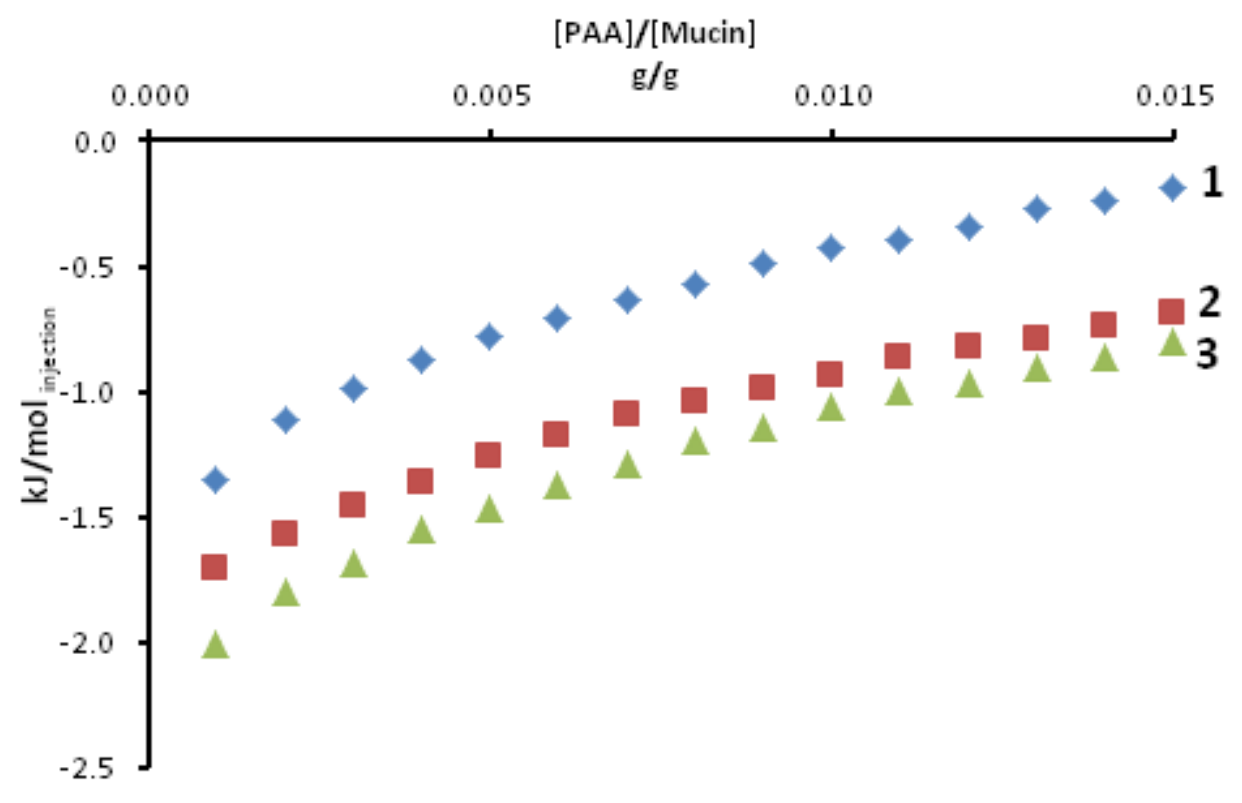

Figure 4 Effect of sonication on the interaction between PGM and PAA studied using ITC. $10 \mathrm{mg} / \mathrm{mL}$ PGM dispersions were sonicated for $0 \mathrm{~min}(1), 5 \mathrm{~min}(2)$ and $15 \mathrm{~min}(3)$ and then were titrated with $1 \mathrm{mg} / \mathrm{mL}$ PAA at $\mathrm{pH}$ 3.0. Error bars are not shown to avoid figure overcrowding. Raw ITC data could be found in Figure 2S (Supporting information). 


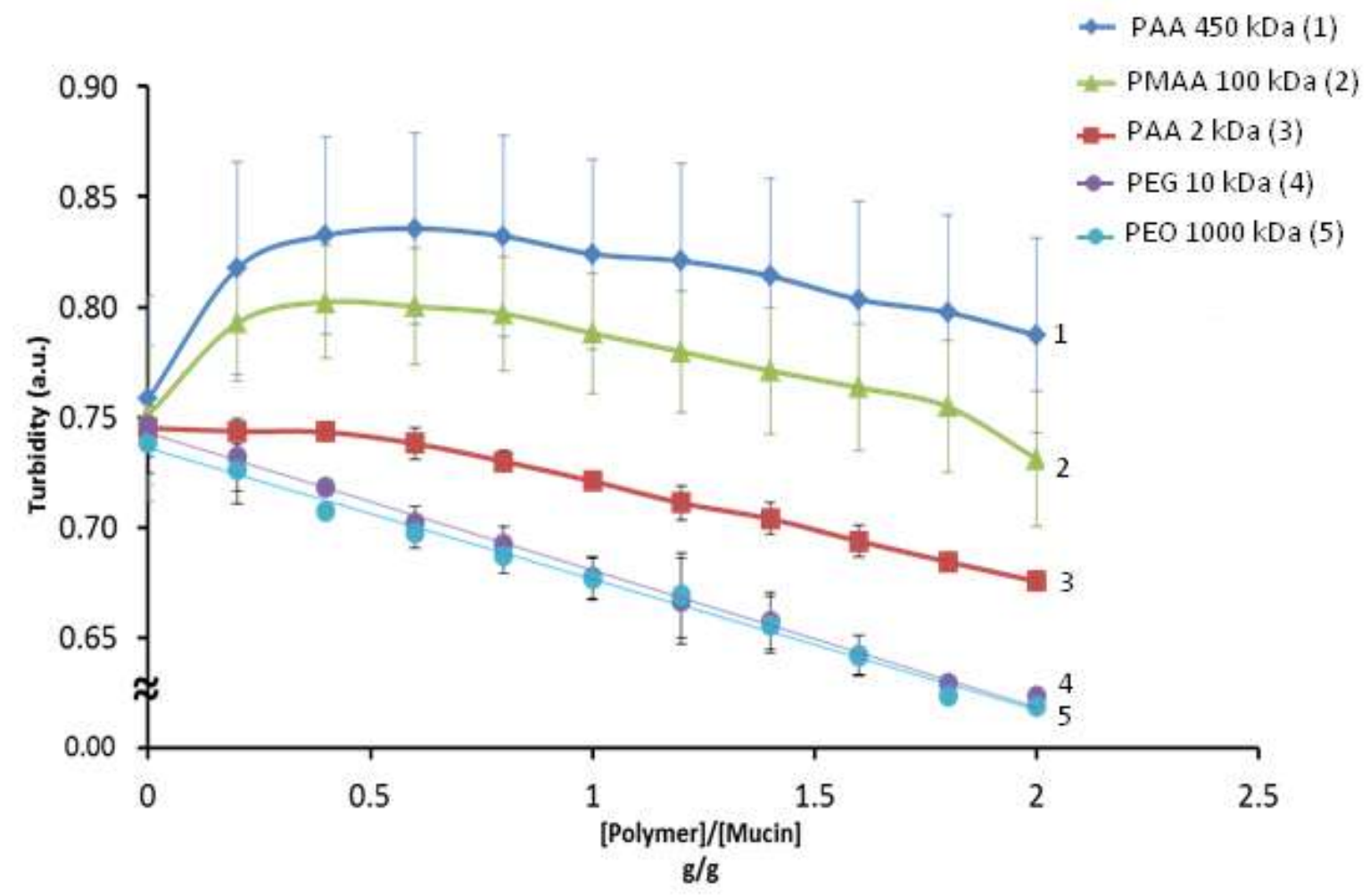

Figure 5 Turbidimetric titration of $1 \mathrm{mg} / \mathrm{mL}$ PGM by $10 \mathrm{mg} / \mathrm{mL}$ solutions of PAA (2 and $450 \mathrm{kDa})$, PMAA (100 kDa), PEG (10 kDa) and PEO (1000 kDa). The values represent the mean \pm SD $(n=3)$. Both dispersions of PGM and solutions of polymers were prepared in phosphate buffer (pH 3.0). 


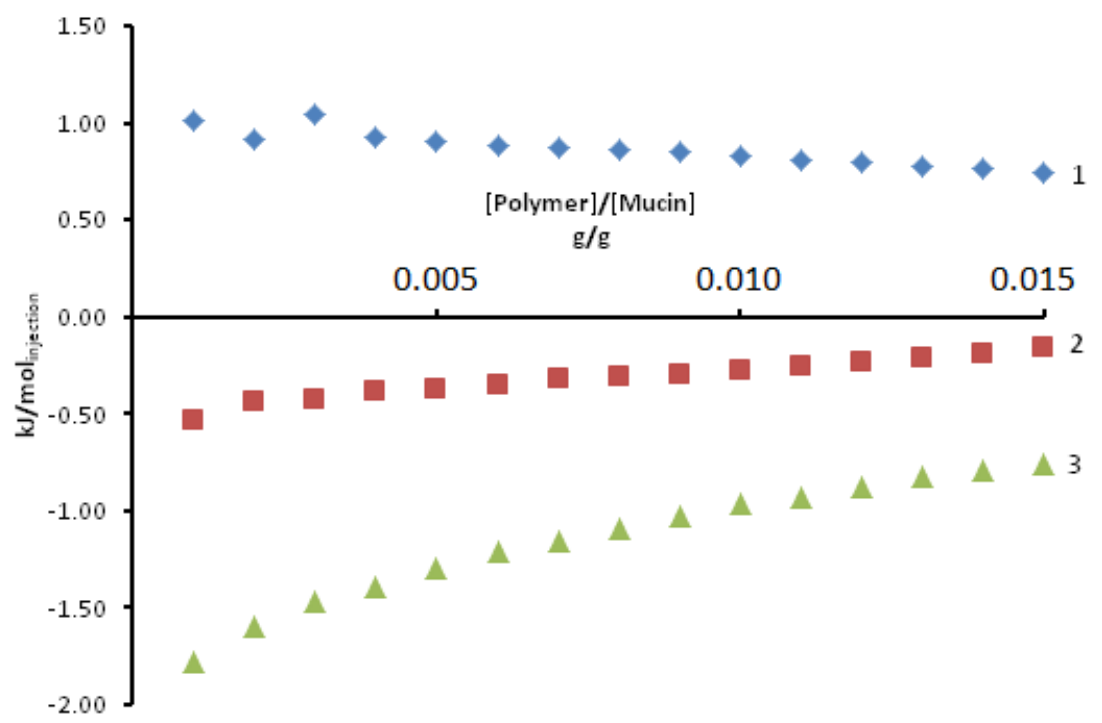

Figure 6 Effect of the nature and molecular weight of poly(carboxylic acids) on the aggregation of mucin using ITC. $1 \mathrm{mg} / \mathrm{mL}$ of PGM was titrated with $10 \mathrm{mg} / \mathrm{mL}$ of PAA 2 kDa (1), PAA $450 \mathrm{kDa}(2)$ and PMAA $100 \mathrm{kDa}$ (3). Phosphate buffer was titrated with 10 $\mathrm{mg} / \mathrm{mL}$ PAA (450 kDa) and used as a control. Raw ITC data could be found in Figure $3 \mathrm{~S}$ (Supporting information). 


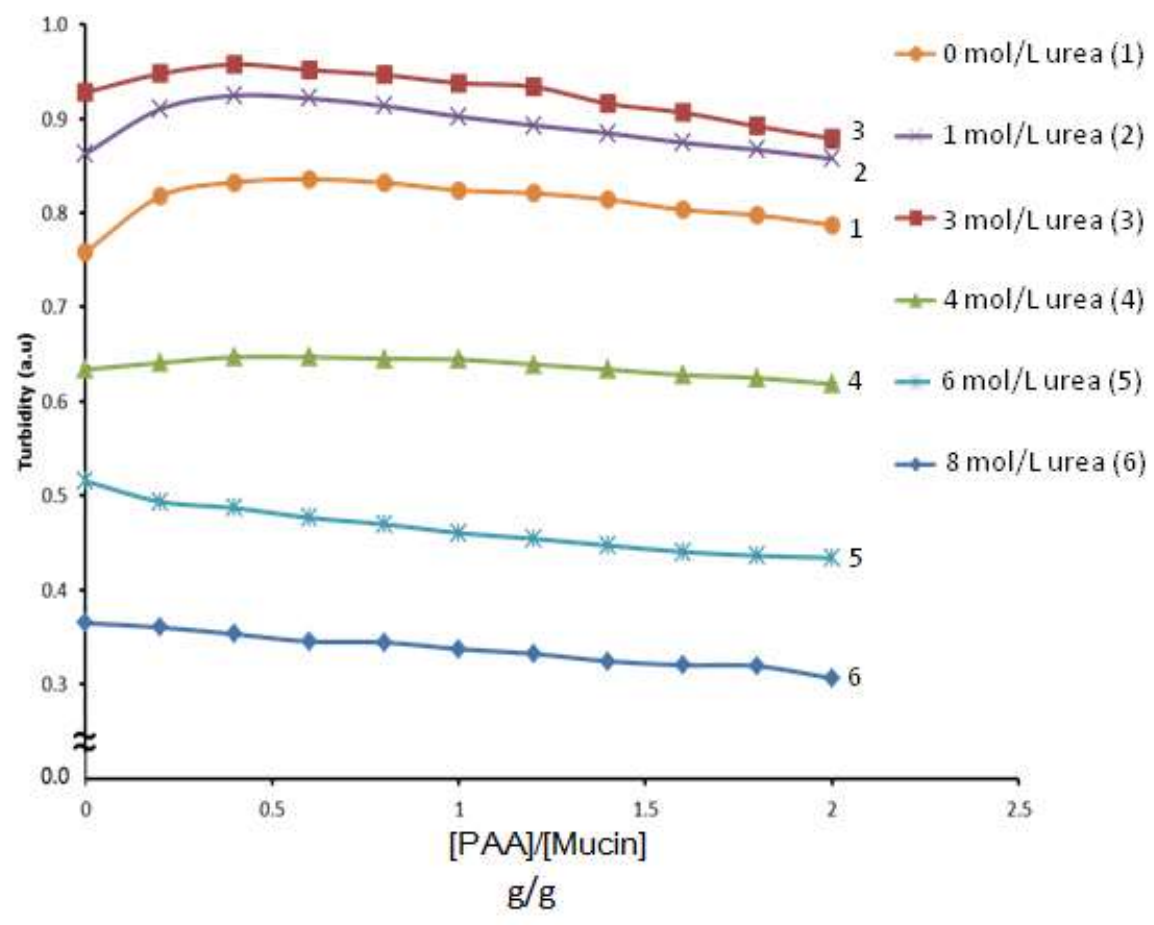

Figure 7 Turbidimetric titration of $1 \mathrm{mg} / \mathrm{mL}$ PGM with $10 \mathrm{mg} / \mathrm{mL}$ PAA (450 kDa) solutions at $\mathrm{pH}$ 3.0. All PGM and PAA dispersions were prepared in solutions with different concentrations of urea $(0-8 \mathrm{~mol} / \mathrm{L})$. Both dispersions of PGM and solutions of polymers were prepared in urea-containing solutions ( $\mathrm{pH} 3.0)$. 


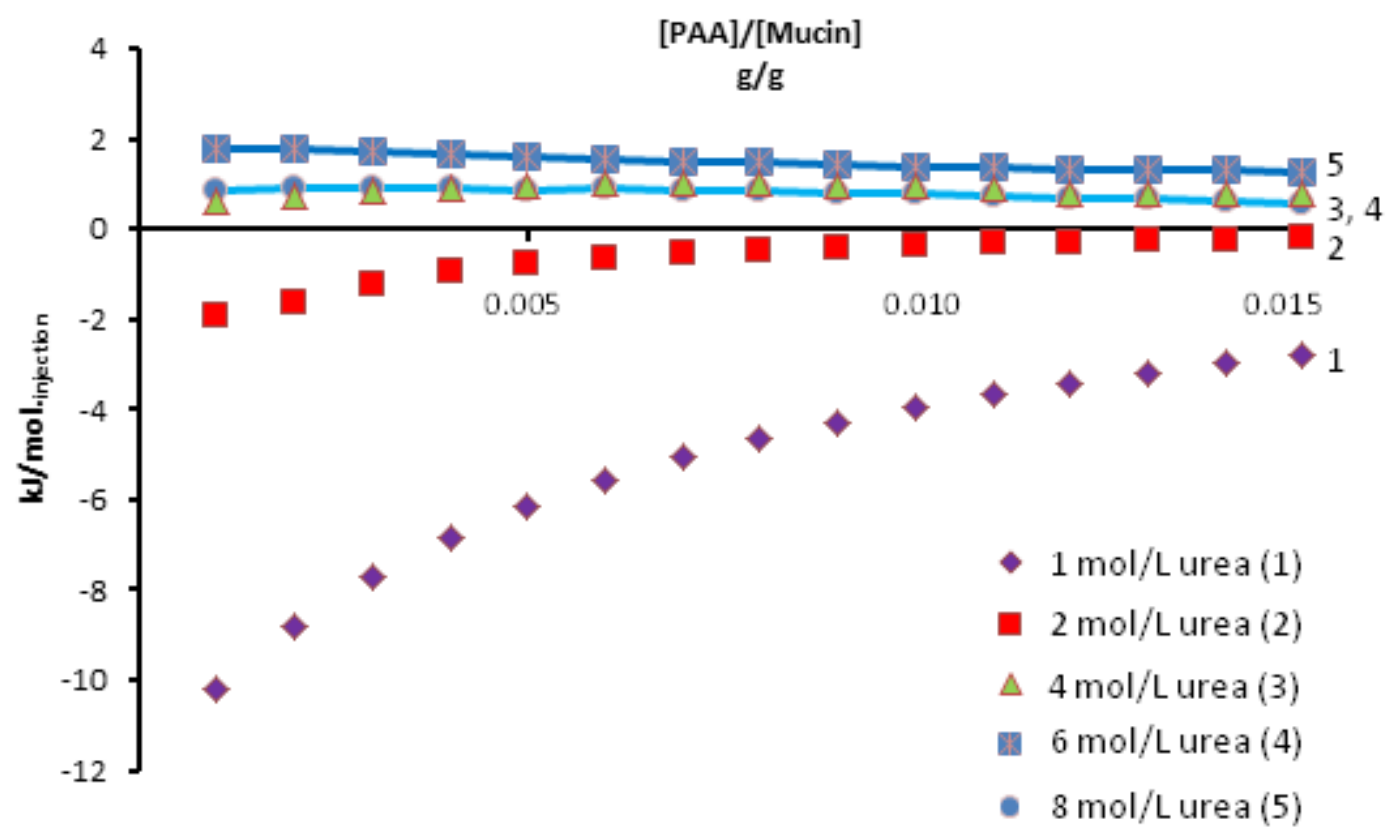

Figure 8 ITC results for titration of $1 \mathrm{mg} / \mathrm{mL}$ PGM dispersions with $10 \mathrm{mg} / \mathrm{mL}$ PAA (450 kDa). All PAA and PGM dispersions were prepared in solutions with different concentrations of urea ( $0-8 \mathrm{~mol} / \mathrm{L})$. Raw ITC data could be found in Figure $5 \mathrm{~S}$ (Supporting information). 


\section{TABLES}

Table 1. ITC analysis of binding affinity $(\mathrm{K})$ and change in enthalpy $(\Delta \mathrm{H})$ for interactions between $14 \mathrm{mM}$ PAA $(450 \mathrm{kDa})$ and $8 \times 10^{3} \mathrm{mM}$ PGM samples.

\begin{tabular}{ccc}
\hline $\begin{array}{c}\text { Time of sample } \\
\text { sonication, } \\
\text { min }\end{array}$ & $\begin{array}{c}\text { Binding affinity, } \\
(\mathbf{K}), \mathbf{M}^{-\mathbf{1}}\end{array}$ & $\begin{array}{c}\mathbf{\Delta H}, \\
\mathbf{k J} / \mathbf{m o l}\end{array}$ \\
\hline 0 & $(4.35 \pm 0.56) \times 10^{4}$ & $-1.14 \pm 0.12$ \\
5 & $(8.16 \pm 0.59) \times 10^{4}$ & $-1.66 \pm 0.08$ \\
15 & $(1.56 \pm 0.20) \times 10^{5}$ & $-2.16 \pm 0.32$ \\
\hline
\end{tabular}

Table 2. ITC analysis of binding affinity $(\mathrm{K})$ and change in enthalpy $(\Delta \mathrm{H})$ for the interactions between poly(carboxylic acids) and $8 \times 103$ mM PGM.

\begin{tabular}{|c|c|c|}
\hline Polymer & $\begin{array}{l}\text { Binding affinity } \\
\text { (K) } \mathbf{M}^{-1}\end{array}$ & $\Delta \mathrm{H}(\mathrm{kJ} / \mathrm{mol})$ \\
\hline PAA $450 \mathrm{kDa}$ & $(1.56 \pm 0.20) \times 10^{5}$ & $-2.16 \pm 0.32$ \\
\hline PAA $2 \mathrm{kDa}$ & $10.19 \pm 1.70$ & $0.02 \pm 0.01$ \\
\hline PMAA $100 \mathrm{kDa}$ & $(1.12 \pm 0.05) \times 10^{3}$ & $-0.91 \pm 0.16$ \\
\hline
\end{tabular}

Table 3. ITC analysis of binding affinity $(\mathrm{K})$ and change in enthalpy $(\Delta \mathrm{H})$ for the interaction between $14 \mathrm{mM}$ PAA $(450 \mathrm{kDa})$ and $8 \times 10^{3} \mathrm{mM}$ PGM in solutions with different urea concentrations.

\begin{tabular}{ccc}
\hline $\begin{array}{c}\text { Concentration of } \\
\text { urea, } \mathbf{~ m o l} / \mathbf{L}\end{array}$ & $\begin{array}{c}\text { Binding affinity } \\
(\mathbf{K}), \mathbf{M}^{-1}\end{array}$ & $\Delta \mathbf{H}(\mathbf{k J} / \mathbf{m o l})$ \\
\hline 1 & $(4.66 \pm 0.44) \times 10^{8}$ & $-11.02 \pm 1.71$ \\
2 & $(8.58 \pm 2.02) \times 10^{3}$ & $-1.90 \pm 0.05$ \\
4 & $(2.10 \pm 0.57) \times 10^{3}$ & $2.07 \pm 0.04$ \\
6 & $(2.57 \pm 0.35) \times 10^{2}$ & $2.40 \pm 0.14$ \\
8 & $(2.06 \pm 0.34) \times 10^{2}$ & $1.96 \pm 0.72$ \\
\hline
\end{tabular}


Table of contents

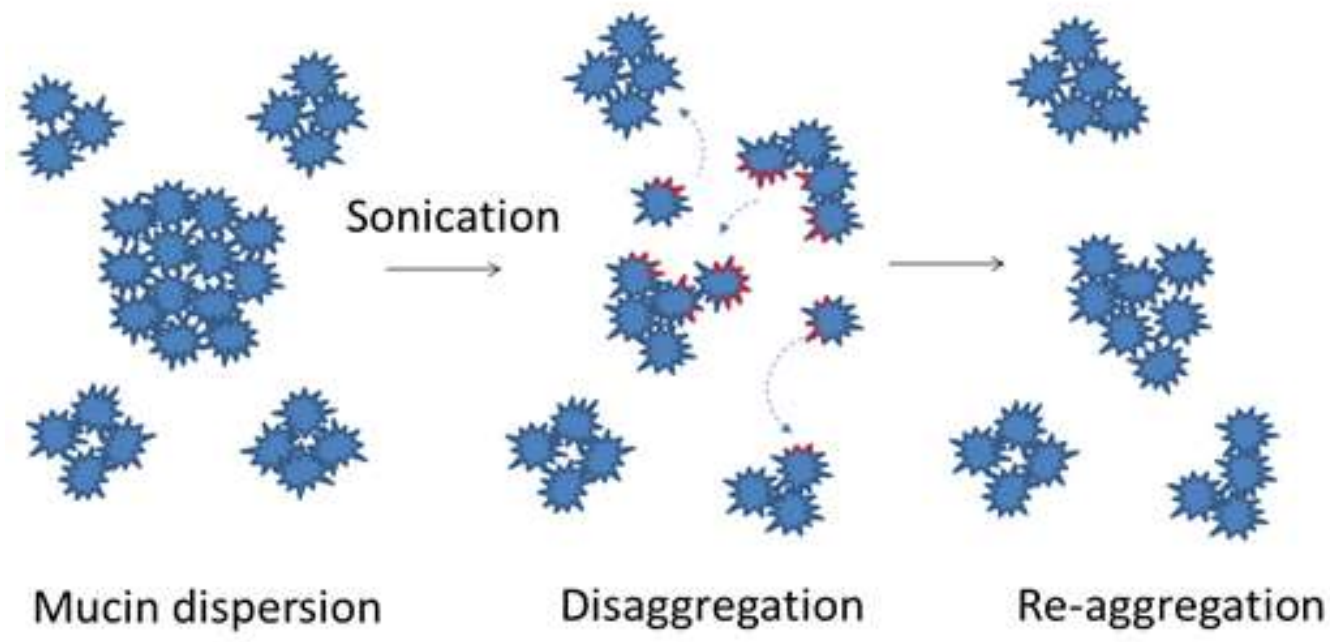

This study reports the structural features of porcine gastric mucin in aqueous dispersions and its interactions with water-soluble polymers. 